\title{
Hamstring injuries and Australian Rules football: over-reliance on Nordic hamstring exercises as a preventive measure?
}

This article was published in the following Dove Press journal:

Open Access Journal of Sports Medicine

\section{Steve Milanese' \\ Roger Eston ${ }^{2}$}

'International Centre for Allied Health Evidence, University of South Australia, Adelaide, South Australia, Australia;

${ }^{2}$ Alliance for Research in Exercise, Nutrition and Activity, University of South Australia, Adelaide, South Australia, Australia
Correspondence: Steve Milanese International Centre for Allied Health Evidence, University of South Australia, City East Campus, GPO Box 247I, Adelaide 5000, SA, Australia

Email steve.milanese@unisa.edu.au

\begin{abstract}
Nordic hamstring exercises (NHE) are promoted as an evidence-based strategy for reducing the prevalence of hamstring injuries in football, with a number of studies showing a significant reduction in hamstring injury rates following implementation of a NHE-based program. However, most of the research to date has been undertaken in soccer with less research carried out in other football codes. Despite this lack of relevant evidence, NHE has recently become popular as a preventative measure in Australian Rules football (ARF) teams; however, hamstring injuries remain high. This paper reviews the literature associated with the use of NHE for ARF players and questions the appropriateness of this exercise approach as a preventative measure for hamstring injuries in this sport. When considering the use of a preventative exercise program, such as the NHE, the specific risks associated with the sporting activity should be considered and the evidence reviewed in light of this. Whilst NHE provides an easy way to do eccentric exercises, the movement does not replicate what is needed in the real world for ARF and should therefore be included in a hamstring injury prevention program in this code with caution.
\end{abstract}

Keywords: Nordic hamstring exercises, prevention, hamstring injury, Australian Rules football

\section{Plain language summary}

Nordic hamstring exercises are widely promoted in football codes as a preventative measure for hamstring injuries. Whilst there is good evidence for its use in some codes of football the evidence associated with the effectiveness of these exercises in Australian Rules Football (ARF) remains less clear. The unique demands of ARF on the athlete compared to other codes makes it difficult to extrapolate the findings from the other football codes to ARF. Due to these differences NHE should be introduced into ARF with caution and form only a small part of a whole ARF specific preventative program.

\section{Introduction}

The Nordic hamstring exercise (NHE), also known as the "Russian hamstring exercise", is widely promoted in the literature for the prevention of hamstring injuries. The exercise involves the athlete leaning forward from a kneeling position, using the hamstring muscles to control the forward motion of the body (see Figure 1). The NHE is commonly performed with the assistance of a partner, who stabilizes the heels/lower legs, or it may be performed with the ankles mechanically anchored. This 


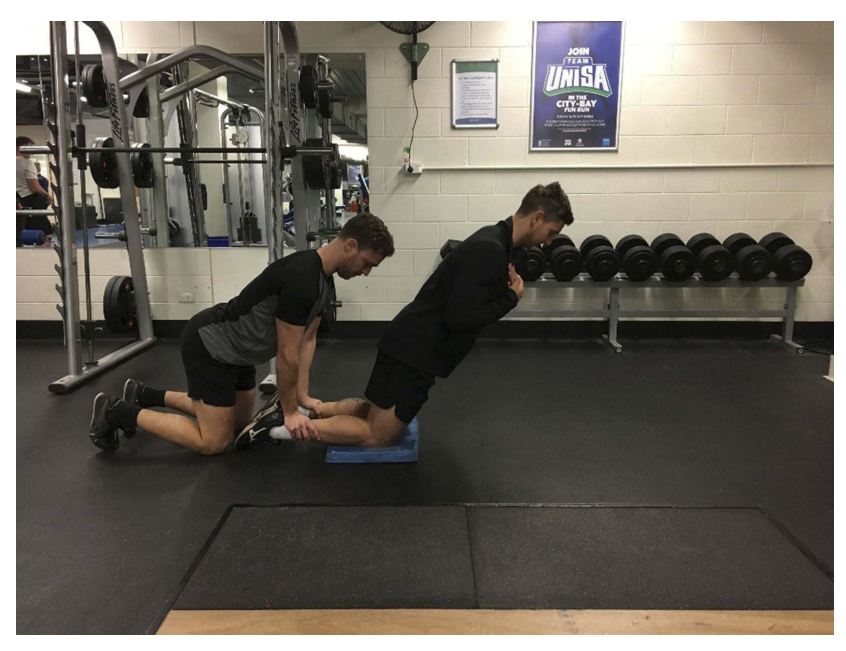

Figure I The Nordic hamstring exercise is commonly executed with a partner who secures the ankles, to allow the participant to lower as far as possible to the floor, before the participant use hands to reach the floor in the final stage.

movement involves eccentric contraction of the hamstrings muscle using a reverse origin-insertion motion. The attraction of NHE is that no equipment is required, making it widely accessible. This review explores the evidence associated with the use of NHE in Australian Rules Football (ARF).

The NHE is recommended as a key exercise to develop hamstring strength in ARF training and lower limb injury prevention guidelines, as evidenced by the "Footy First" training program. ${ }^{1}$ Developed in 2011 by the National Guidance for Australian Football Partnerships and Safety Project research team, the "Footy First" training program is endorsed by the Australian Football League (AFL) Medical Officers Association, AFL Physiotherapists Association and the AFL Sports Science Association. This program prescribes the NHE as the primary exercise in each of the five 4-week duration levels of training across a 3-4month graduated training program. For example, it is prescribed in the following repetition doses of $6 ; 2 \times 5$; $2 \times 8 ; 2 \times 10$ and $2 \times 12$ repetitions, across 5 progressive training levels, completed twice a week for 20 weeks. The stated specific aim of the NHE is to strengthen the hamstrings to help prevent against hamstring injury.

\section{Hamstring injury mechanisms}

Hamstring injuries occur most commonly at the end of swing phase, when substantial hamstring eccentric contraction occurs to decelerate hip flexion and knee extension $^{2,3}$ or at the initial stage of the stance phase ${ }^{4}$ when the hamstrings act as a transducer of power from the knee and hip joint against the ground reaction force. ${ }^{3}$ Whilst hamstrings have a relatively high proportion of fast twitch type II muscle fibers which can produce large forces, ${ }^{5,6}$ their bi-articular nature makes them susceptible to strain during the powerful eccentric muscle contractions seen at the end of the swing phase of running. ${ }^{7}$ This ballistic open chain movement, also seen after an athlete kicks a ball and controls the forward momentum of the leg, is known to preferentially recruit multi-joint muscles like the hamstrings. ${ }^{8}$ At the initial stage of the stance phase of sprinting, hamstring injuries are potentially more likely in athletes with poor technique or gluteus maximus weakness, as the gluteus maximus should be the primary hip extensor in sprinting. ${ }^{9}$ If the gluteus maximus is weak, the hamstrings may be required to contribute more force to hip extension, potentially predisposing to injury. ${ }^{3}$

Functionally, hamstring injuries occur most commonly when accelerating and/or running at maximum speed ${ }^{10-12}$ with the functional demands on the hamstring muscles differing during these two running demands. During the terminal mid-swing of maximum-speed sprint, the semitendinosus (ST) muscle shows higher activation than that of the biceps femoris long head (BF(lh)), ${ }^{13}$ whilst in the early stance phase of the acceleration sprint, the relative EMG activation of the $\mathrm{BF}(\mathrm{lh})$ muscle is significantly higher than that of the ST. ${ }^{13}$

Opar et $\mathrm{al}^{14}$ measured eccentric hamstring strength in professional ARF players at the commencement and conclusion of preseason training and at the midpoint of the season. They showed that low levels of eccentric hamstring strength increased the risk of hamstring strain injury.

\section{Hamstring injury prevention in ARF}

A number of studies have suggested that a program of NHE was effective in reducing hamstring injury rates in a range of football codes, such as rugby ${ }^{15}$ and soccer. ${ }^{16-18}$ Arnason et $\mathrm{al}^{16}$ reported that hamstring strains were $65 \%$ lower in soccer teams that used an NHE training program, compared to teams that used hamstring flexibility training programs alone $(p<0.01)$. A systematic review and metaanalysis on the effectiveness of injury prevention programs in soccer also reported a considerably reduced risk (risk ratio: $0.490(95 \% \mathrm{CI} 0.291-0.827, p=0.008))$ of hamstring injury in those programs that included NHE compared to control programs. ${ }^{19}$

The AFL reports the injury incidence for new hamstring injuries per club per season as averaging 5.14 new injuries between 2013 and $2017 .^{20}$ Whilst the use of NHE training to 
increase hamstring strength is tempting in ARF, the evidence for its use in reducing the risk of hamstring injury remains mainly in the domain of soccer, with very few studies assessing the efficacy of NHE in reducing hamstring injury in ARF. Gabbe et $\mathrm{al}^{21}$ assessed the effects of eccentric exercise on the occurrence of hamstring strain injuries in amateur players from seven ARF clubs, with 114 athletes in the intervention and 106 in the control group. NHE produced significant postexercise soreness in this study, possibly due to the very high volume (12 sets of 6 repetitions) and lack of gradual progression. Consequently, there was very poor compliance by the intervention group and no statistically significant effect detected, although the intervention showed a trend towards preventing hamstring injuries $(p=0.098)$. The authors recommended that a modified eccentric exercise program that produced less delayed onset muscle soreness be considered for future investigation.

ARF shares many traits with soccer, as both can be characterized by regular running/walking, with intensity ranging from short duration maximal effort sprints to low-level jogging, and both involve kicking a ball. However, whilst the kicking action starts in a similar position, in ARF kicking typically ends with a much higher level of hip flexion and through a far greater range of movement, as the player kicks the ball from his/her hand and usually aims high - resulting in a longer follow through of the kicking leg. Ball ${ }^{22}$ reported an average hip angle of 216 degrees (SD 16 deg.) during AFL distance kicking whilst Shan and Westerhoff ${ }^{23}$ reported a hip angle of 130 degrees ( $\pm 10 \mathrm{deg})$ during maximal instep kicking in male soccer players (see Figures 2 and 3). In both kicking actions, the knee is approaching full extension, suggesting that hamstrings are at a greater stretch during ARF kicking.

ARF also has several other fundamental characteristics which are distinct from soccer and which affect the hamstrings differently. For example, ARF involves frequent bending forward to pick the ball up from the ground whilst running at pace, requiring the hamstrings to operate in a considerably lengthened position, particularly over the hip joint.

\section{Effect of NHEs on hamstring performance}

Performance of NHE has been shown to have a number of effects on muscle performance and architecture. The NHE elicits changes in muscle performance and mid-range torque dynamics which could be effective in reducing hamstring injuries. For example, Mjolsnes et $\mathrm{al}^{24}$ reported an $11 \%$ increase in eccentric torque of the hamstrings $(p<0.01)$ after 10 weeks of NHE training in well-trained

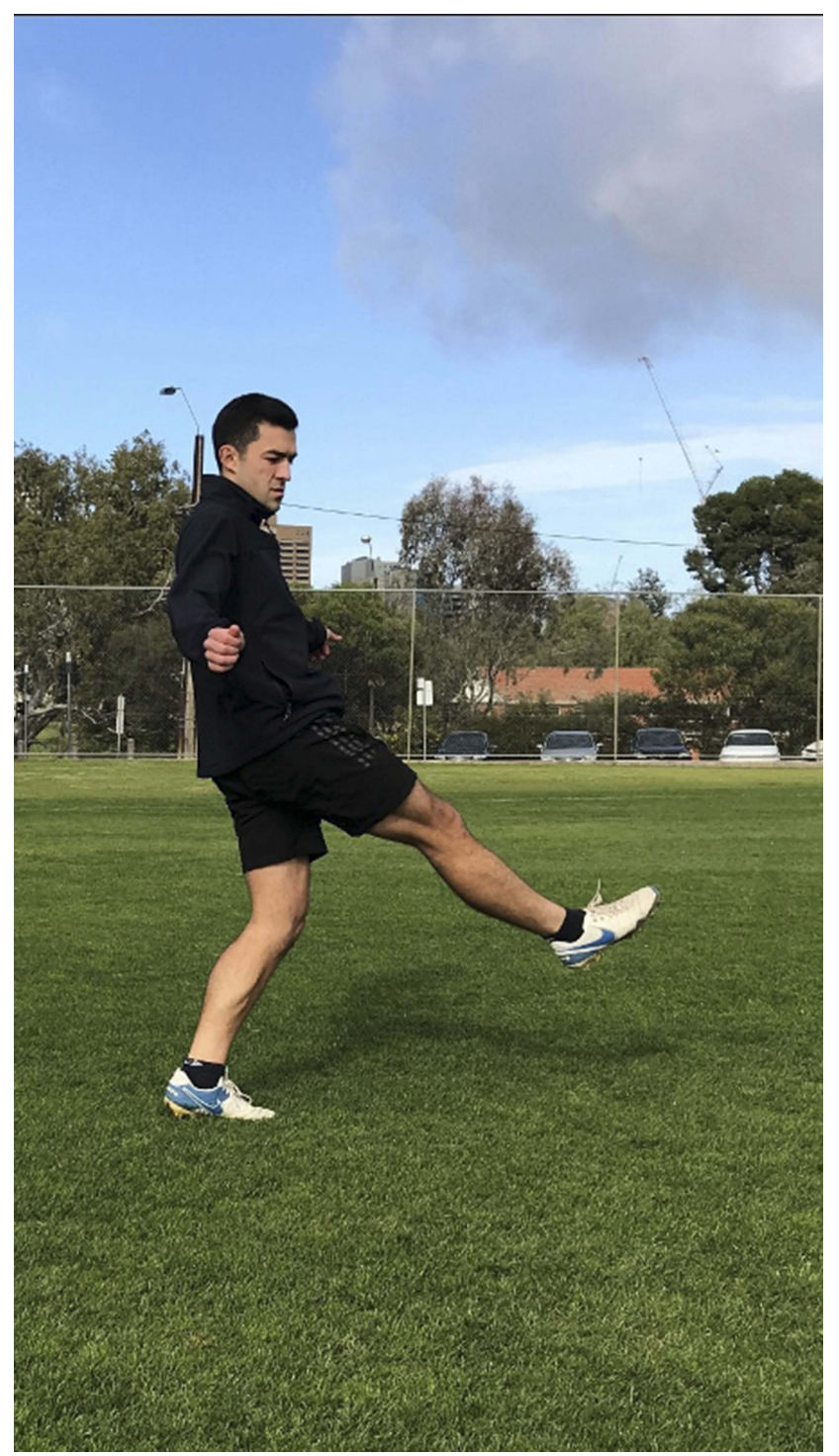

Figure 2 Example of typical degree of hip flexion and knee extension in a soccer kick.

soccer players as well as a 7\% increase in isometric hamstring strength at 90, 60 and 30 degrees from full knee extension. Similar results were reported by Alt et $\mathrm{al}^{25}$ who reported a $6-14 \%$ gain and by Delahunt et $\mathrm{al}^{26}$ who reported a $7 \%$ increase in eccentric hamstring strength following a 4-week and 6-week NHE program, respectively. Seymore et $\mathrm{al}^{27}$ on the other hand reported no increase in eccentric hamstring strength following a 6week NHE program despite increases in muscle CSA.

Reflecting the specificity of exercises such as NHE, these changes in hamstring eccentric strength were accompanied by changes in the position of peak torque. Clark et $\mathrm{al}^{28}$ reported a $19 \%$ increase in the position of peak torque knee flexion angle toward full knee extension ( 32 cf. $26 \mathrm{deg}$, 


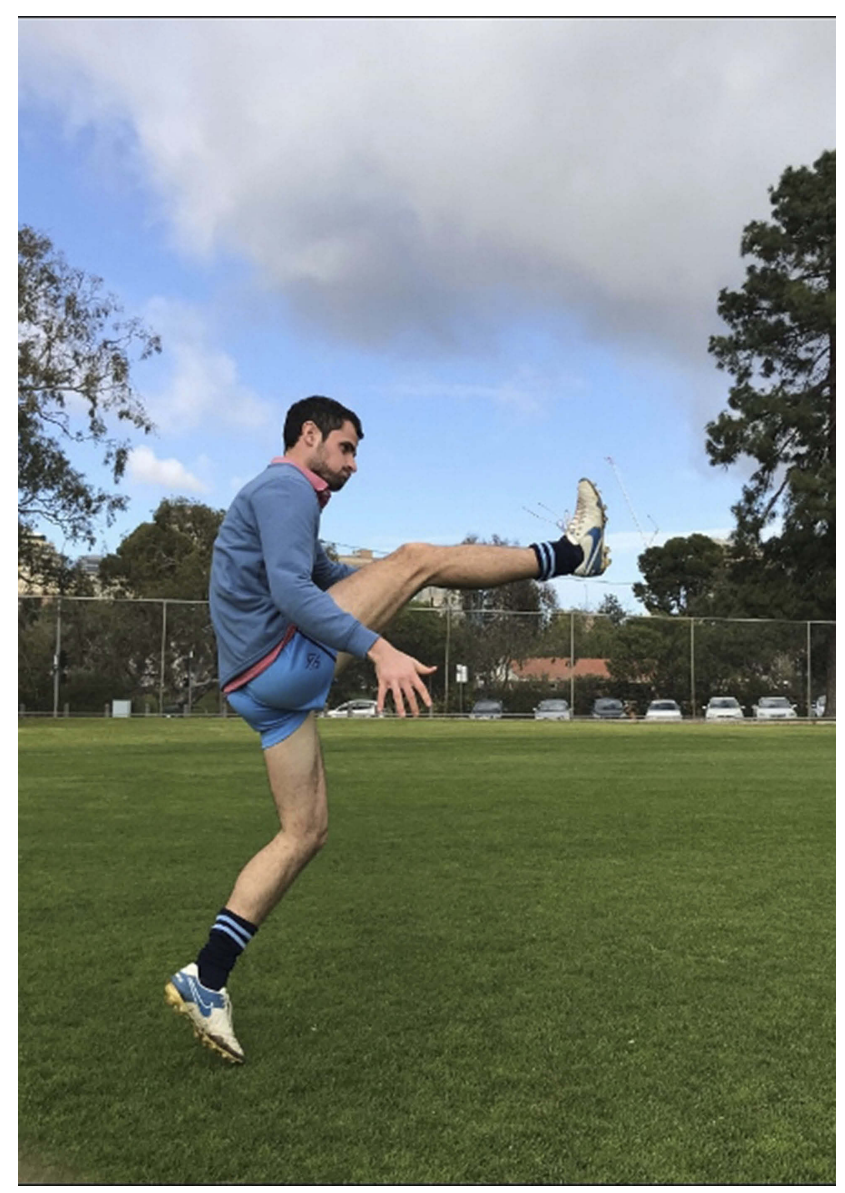

Figure 3 Example of typical degree of hip flexion and knee extension during an ARF kick. The ARF kick typically ends with much higher level of hip flexion, requiring a much greater level of hamstring extension compared to soccer.

$p<0.01$ ) following NHE performed twice weekly for four weeks in amateur ARF players. This is indicative of a rightward shift in the length-tension curve of hamstrings function toward knee extension. This is not surprising, as the NHE involves a very limited range of hip movement with the main action of the hamstrings involving control of the degree of knee flexion, with the hip maintained at a relatively fixed angle. The effect of the NHE on hamstring eccentric strength and position of peak torque during functional activities involving knee extension and hip flexion as seen during high speed running and ARF kicking remains unclear.

Mjolsnes et $\mathrm{al}^{24}$ observed an $11 \%$ increase in the hamstrings: quadriceps ratio (from 0.89 to $0.98, p<0.01$ ) in the NHE group compared to a traditional hamstring curl exercise over a 10-week period, which they reported reflected the lack of effect on concentric quadriceps contraction. This was in contrast to Clark et $\mathrm{al}^{28}$ who reported an $11.3 \%$ decrease in maximal quadriceps concentric torque, despite a $6.6 \%$ increase in vertical jump height, following a 4-week NHE program. The authors suggested that this may reflect changes in the viscoelastic properties of the muscular unit or increased antagonistic activation of the hamstrings during the open chain concentric quadriceps testing protocol.

Approximately $80 \%$ of hamstring strain injuries involve lesions within the biceps femoris long head $(\mathrm{BF}(\mathrm{lh})$, and NHE is reported to be effective at reducing these injuries in soccer players. ${ }^{17,18}$ However, it has been argued that NHE may be suboptimal for injury prevention as it involves preferential activation of the ST and biceps femoris short head (BH(sh)) muscles, ${ }^{29}$ as indicated by the considerably greater increase in muscle cross-sectional area resulting from NHE training in these muscles compared to the biceps femoris long head. Mendiguchia et $\mathrm{al}^{30}$ reported greater changes in $\mathrm{BF}$ (sh) on MRI after NHE whilst Bourne et $\mathrm{al}^{31}$ reported that NHE recruited ST more than other hamstring muscles with an increase in MRI T2 imaging of $16.8 \%, 15.8 \%$ and $20.2 \%$ greater than $\mathrm{BF}(\mathrm{lh}), \mathrm{BF}(\mathrm{sh})$ and semimembranosus muscle (SM), respectively.

Clark et $\mathrm{al}^{28}$ also reported a significant difference in the effect of the NHE between dominant and nondominant legs with the limb with the initially higher knee extension torque angle benefitting most from the NHE. They hypothesized that as the athlete lowers themselves forwards, the limb with the higher knee extension angle of peak hamstring torque will be working harder. This greater overload on the already dominant hamstring may result in enhanced neuromuscular adaptation in this limb, which may further increase the magnitude of imbalance between the limbs. Similar results were identified by Mendiguchia et $\mathrm{al}^{30}$ who, using MRI of soft tissue changes following NHE, identified asymmetrical and nonuniform signaling between hamstring muscles in the dominant and nondominant legs. This presents a potential disadvantage and limitation to bilateral eccentric hamstring training, such as the NHE.

It is unknown, and we believe highly unlikely that NHE leads to hypertrophy and increased strength of the hamstrings muscle during eccentric knee flexion and hip extension in the fully extended end range of movement of the hamstrings where the muscle is at its weakest and most vulnerable. In the NHE, the hip is maintained in neutral and therefore the hamstrings never work in a position of full knee extension AND hip flexion. It has been proposed that exercise at longer muscle lengths than those observed during the NHE may be more effective at increasing hamstring fascicle length, ${ }^{32,33}$ an apparent risk factor for hamstring injury. ${ }^{34}$ 
Another potential area of concern is the effect of a high load eccentric program such as the NHE. Gabbe et $\mathrm{al}^{21}$ in a group of community-level ARF players found that the acute impact of eccentric training - such as that involved in NHE, commonly invokes the onset of considerable delayed muscle soreness on movement, tenderness to touch, muscle weakness and reduction in range of motion, particularly in the early stages of training. ${ }^{39}$ The exerciseinduced muscle damage associated with eccentric exercise is manifested in short-term performance decrements in power output, strength, jump height, sprinting, balance, agility and range of motion, ${ }^{40-43}$ all factors which are key in ARF.

Eccentric exercise-induced muscle damage peaks $72 \mathrm{hrs}$ following exercise and can take up to 5-7 days to return to normal. ${ }^{44}$ As the short-term impact of eccentric exercise in the early stages of a training program can affect performance for an extended period of time after a strenuous bout of eccentric exercise before full recovery, the scheduling, intensity and timing of NHE during the season and between matches are critical. Importantly, research on young female adults has shown that strength loss resulting from eccentric exercise outlasts the incidence of pain and soreness. ${ }^{45}$ In their study, isometric strength of the elbow flexors remained over $20 \%$ lower 11 days after the initial bout of eccentric exercise $(P<0.01)$, despite the absence of any pain on movement. The absence of pain may reduce awareness of the longer lasting muscle weakness and increase vulnerability to injury, particularly when the muscle is exposed to high forces at long or short muscle lengths. Whilst the post-eccentric muscle soreness is magnified in less trained individuals compared to trained athletes, the post-exercise changes related to heavyloaded eccentric exercises in well-trained individuals remain unknown. Mendiguchia et al ${ }^{30}$ identified post-NHE changes in $\mathrm{BF}$ (sh) using MRI $72 \mathrm{hrs}$ after a set of $5 \times 8$ repetitions in national-level athletes.

\section{Effect of NHE on hamstring morphology}

Contrary results have been found related to the effect of NHE on fascicle length;, NHE has been shown not to increase hamstring fascicle length over a 6 -week period. ${ }^{15}$ Guex et $\mathrm{al}^{35}$ found that NHE increased fascicle length over a 3-week program, but not as much as eccentric exercises performed in hip flexion (fascicle length increase $4.9 \% \mathrm{cf}$ $9.3 \%, p<0.001)$. Bourne et $\mathrm{al}^{29}$ reported increases in $\mathrm{BH}$ (lh) fascicle length following NHE but no more than with a hip extension eccentric exercise program over 5 weeks. Increases in $\mathrm{BH}(\mathrm{lh})$ fascicle length following NHE have also been reported by Presland et al, ${ }^{36}$ Alonso-Fernandez et $\mathrm{al}^{37}$ and Lovell et al. ${ }^{38}$ However, none of these studies compared the fascicle length changes to other eccentric exercise programs.

We believe that a focus on NHE as a significant component of a hamstring prevention intervention may not be the answer to the current high incidence of hamstring injury in ARF. Clinicians should account for the complex neuromuscular mechanisms within the hamstring muscle unit, particularly involving the $\mathrm{BF}(\mathrm{lh})$ and theST muscles, during both prevention and rehabilitation programs.

\section{Practical applications}

Sports-specific (and movement-specific) training is critical for ARF. Whilst the NHE provides a convenient way to do eccentric exercises, the movement does not replicate what is needed in the real world for ARF. In ARF, the hamstrings are required to work to control the momentum of the kicking leg as it flexes to end-range hip flexion and knee extension in an open kinetic chain activity with a fixed origin. This range of hip movement and subsequent lengthening of the hamstrings are much greater in ARF compared to a typical kick in soccer. ARF also requires a strong eccentric/concentric contraction as the player leans forward to pick a ball up on the run, involving a closed kinetic chain, reverse origin insertion motion. All of these require high levels of neuromuscular control between the BF(lh) and ST. We believe the NHE should therefore form only a small part of a more holistic hamstring injury prevention program, along the lines which have been recommended more recently for soccer. ${ }^{46,47}$ This preventative program should consider the specificity of movement in ARF, such as high-speed running, high-speed accelerations and recognition of the need for both knee flexor and hip extensor strength (NHE effective for the former but not the latter).

\section{Conclusions}

The NHE does not provide the benefits of sports specificity and therefore should be included with caution in a hamstring injury prevention program in ARF. Specific issues associated with NHE include the following:

(a) The NHE does not exercise the hamstring group of muscles into their elongated range,

(b) The NHE focusses on knee flexor eccentric muscle torque, not hip extensor eccentric muscle torque, ,

(c) In high dosages, the NHE may lead to muscle weakness and changes in muscle performance that last up to $72 \mathrm{hrs}$ post exercises, 
(d) The hamstring neuromuscular recruitment pattern during NHE may not reflect the pattern required during functional activity required in ARF.

\section{Consent for publication}

All photographs were obtained following written informed consent.

\section{Author contributions}

All authors contributed to data analysis, drafting and revising the article, gave final approval of the version to be published, and agree to be accountable for all aspects of the work.

\section{Disclosure}

The authors report no conflicts of interest in this work.

\section{References}

1. Australian Football League. National guidance for Australian football partnerships and safety project research team 'Footy First'; 2018. Available from: http://www.aflcommunityclub.com.au/index.php?id= 906. Accessed March 18, 2019.

2. Montgomery WH III, Pink M, Perry J. Electromyographic analysis of hip and knee musculature during running. Am J Sports Med. 1994;22 (2):272-278. doi:10.1177/036354659402200220

3. Hoskins W, Pollard H. The management of hamstring injury—part 1 : issues in diagnosis. Man Ther. 2005;10(2):96-107. doi:10.1016/j. math.2005.03.006

4. Orchard JW. Hamstrings are most susceptible to injury during the early stance phase of sprinting. Br J Sports Med. 2012;46:88-89. doi:10.1136/bjsports-2011-090127

5. Garrett WE, Califf JC, Bassett FH. Histochemical correlates of hamstring injuries. Am J Sports Med. 1984;12(2):98-103. doi:10.1177/ 036354658401200202

6. Noonan TJ, Garrett WE. Muscle strain injury: diagnosis and treatment. J Am Acad Orthop Surg. 1999;7(4):262-269. doi:10.5435/ 00124635-199907000-00006

7. Brockett CL, Morgan DL, Proske UWE. Predicting hamstring strain injury in elite athletes. Med Sci Sports Exerc. 2004;36(3):379-387. doi:10.1249/01.MSS.0000117165.75832.05

8. Richardson C, Bullock MI. Changes in muscle activity during fast, alternating flexion-extension movements of the knee. Scand $J$ Rehabil Med. 1986;18(2):51-58.

9. Simonsen EB, Thomsen L, Klausen K. Activity of mono-and biarticular leg muscles during sprint running. Eur J Appl Physiol Occup Physiol. 1985;54(5):524-532.

10. Sherry MA, Best TM. A comparison of 2 rehabilitation programs in the treatment of acute hamstring strains. J Orthop Sports Phys Ther. 2004;34(3):116-125. doi:10.2519/jospt.2004.34.3.116

11. Woods C, Hawkins RD, Maltby S, Hulse M, Thomas A, Hodson A. The Football Association Medical Research Programme: an audit of injuries in professional football-analysis of hamstring injuries. $\mathrm{Br}$ Sports Med. 2004;38(1):36-41. doi:10.1136/bjsm.2002.002352

12. Bourne MN, Timmins RG, Opar DA, et al. An evidence-based framework for strengthening exercises to prevent hamstring injury. Sports Med. 2018;48(2);251-267.
13. Higashihara A, Nagano Y, Ono T, Fukubayashi T. Differences in hamstring activation characteristics between the acceleration and maximum-speed phases of sprinting. $J$ Sports Sci. 2018;36 (12):1313-1318. doi:10.1080/02640414.2017.1375548

14. Opar DA, Williams MD, Timmins RG, Hickey J, Duhig SJ, Shield AJ. Eccentric hamstring strength and hamstring injury risk in Australian footballers. Med Sci Sports Exerc. 2015;47:857-865. doi:10.1249/MSS.0000000000000465

15. Brooks JH, Fuller CW, Kemp SP, Reddin DB. Incidence, risk, and prevention of hamstring muscle injuries in professional rugby union. Am J Sports Med. 2006;34(8):1297-1306. doi:10.1177/0363546505 286022

16. Arnason A, Andersen TE, Holme I, Engebretsen L, Bahr R. Prevention of hamstring strains in elite soccer: an intervention study. Scand J Med Sci Sports. 2008;18(1):40-48. doi:10.1111/j.1600-0838.2006.00634.x

17. Petersen J, Thorborg K, Nielsen MB, Budtz-Jørgensen E, Hölmich P. Preventive effect of eccentric training on acute hamstring injuries in men's soccer: a cluster-randomized controlled trial. Am J Sports Med. 2011;39(11):2296-2303. doi:10.1177/ 0363546511419277

18. van der Horst N, Smits DW, Petersen J, Goedhart EA, Backx JG. The preventive effect of the Nordic hamstring exercise on hamstring injuries in amateur soccer players: a randomized controlled trial. Am J Sports Med. 2015;43:1316-1323. doi:10.1177/0363546-515574057

19. Al Attar WSA, Soomro N, Sinclair PJ, Pappas E, Sanders RH. Effect of injury prevention programs that include the Nordic hamstring exercise on hamstring injury rates in soccer players: a systematic review and metaanalysis. Sports Med. 2017;47(5):907-916. doi:10.1007/s40279-0160638-2

20. AFL Injury Survey. 26th Annual AFL injury survey; 2017. Available from: http://www.afl.com.au/staticfile/AFL\%20Tenant/ 2017AFLInjuryReport.pdf. Accessed March 19, 2019.

21. Gabbe BJ, Branson R, Bennell KL. A pilot randomised controlled trial of eccentric exercise to prevent hamstring injuries in community-level Australian Football. J Sci Med Sport. 2006;9(1-2):103109. doi:10.1016/j.jsams.2006.02.001

22. Ball K. Biomechanical considerations of distance kicking in Australian rules football. Sports Biomech. 2008;7(1):10-23. doi:10.1080/147631 40701683015

23. Shan G, Westerhoff P. Soccer: full-body kinematic characteristics of the maximal instep soccer kick by male soccer players and parameters related to kick quality. Sports Biomech. 2005;4(1):59-72. doi:10.1080/14763140508522852

24. Mjølsnes R, Arnason A, Østhagen T, Raastad T, Bahr R. A 10week randomized trial comparing eccentric vs. concentric hamstring strength training in well-trained soccer players. Scand $J$ Med Sci Sports. 2004;14(5):311-317. doi:10.1046/j.1600-0838. 2003.367.x

25. Alt T, Nodler YT, Severin J, Knicker AJ, Strüder HK. Velocityspecific and time-dependent adaptations following a standardized Nordic Hamstring exercise training. Scand J Med Sci Sports. 2018;28(1):65-76. doi:10.1111/sms. 12868

26. Delahunt E, McGroarty M, De Vito G, Ditroilo M. Nordic hamstring exercise training alters knee joint kinematics and hamstring activation patterns in young men. Eur J Appl Physiol. 2016;116(4):663-672. doi:10.1007/s00421-015-3325-3

27. Seymore KD, Domire ZJ, DeVita P, Rider PM, Kulas AS. The effect of Nordic hamstring strength training on muscle architecture, stiffness, and strength. Eur J Appl Physiol. 2017;117(5):943-953. doi:10.1007/s00421-017-3583-3

28. Clark R, Bryant A, Culgan JP, Hartley B. The effects of eccentric hamstring strength training on dynamic jumping performance and isokinetic strength parameters: a pilot study on the implications for the prevention of hamstring injuries. Phys Ther Sport. 2005;6(2):6773. doi:10.1016/j.ptsp.2005.02.003 
29. Bourne MN, Duhig SJ, Timmins RG, et al. Impact of the Nordic hamstring and hip extension exercises on hamstring architecture and morphology: implications for injury prevention. $\mathrm{Br} J$ Sports Med. 2017;51:469-477. doi:10.1136/bjsports-2016-096130

30. Mendiguchia J, Arcos AL, Garrues MA, Myer GD, Yanci J, Idoate F. The use of MRI to evaluate posterior thigh muscle activity and damage during Nordic hamstring exercise. J Strength Cond Res. 2013;27 (12):3426-3435. doi:10.1519/JSC.0b013e31828fd3e7

31. Bourne MN, Opar DA, Williams MD, Al Najjar A, Shield AJ. Muscle activation patterns in the Nordic hamstring exercise: impact of prior strain injury. Scand J Med Sci Sports. 2016;26(6):666-674. doi:10.1111/ sms. 12494

32. Guex K, Millet GP. Conceptual framework for strengthening exercises to prevent hamstring strains. Sports Med. 2013;43(12):12071215. doi:10.1007/s40279-013-0097-y

33. Van Hooren B, Bosch F. Is there really an eccentric action of the hamstrings during the swing phase of high-speed running? part I: a critical review of the literature. $J$ Sports Sci. 2017;35(23):2313-2321. doi:10.1080/02640414.2016.1266018

34. Timmins R, Bourne M, Shield A, Williams MD, Lorenzen C, Opar DA. Short biceps femoris fascicles and eccentric knee flexor weakness increase the risk of hamstring injury in elite football (soccer): a prospective cohort study. Br J Sports Med. 2016;50:1524-1535. doi:10.1136/bjsports-2016-096014

35. Guex K, Degache F, Morisod C, Sailly M, Millet GP. Hamstring architectural and functional adaptations following long vs. short muscle length eccentric training. Front Physiol. 2016;7:340. doi:10.3389/fphys.2016.00340

36. Presland JD, Timmins RG, Bourne MN, Williams MD, Opar DA. The effect of Nordic hamstring exercise training volume on biceps femoris long head architectural adaptation. Scand J Med Sci Sports. 2018;28(7):1775-1783. doi:10.1111/sms.13085

37. Alonso-Fernandez D, Docampo-Blanco P, Martinez-Fernandez J. Changes in muscle architecture of biceps femoris induced by eccentric strength training with nordic hamstring exercise. Scand J Med Sci Sports. 2018;28(1):88-94. doi:10.1111/sms.12877
38. Lovell R, Knox M, Weston M, Siegler JC, Brennan S, Marshall PW. Hamstring injury prevention in soccer: before or after training? Scand J Med Sci Sports. 2018;28(2):658-666. doi:10.1111/ sms. 12925

39. Byrne C, Twist C, Eston RG. Neuromuscular function after exercise-induced muscle damage: theoretical and applied implications. Sports Med. 2004;34:49-69. doi:10.2165/00007256-20043 4010-00005

40. Highton J, Twist C, Eston RG. The effects of exercise-induced muscle damage on agility and sprint running performance. $J$ Exerc Sci Fit. 2009;7(1):24-30. doi:10.1016/S1728-869X(09)60004-6

41. Twist C, Gleeson NP, Eston RG. The effects of exercise-induced muscle damage on unilateral balance performance. J Sports Sci. 2008;26:1073-1080. doi:10.1080/02640410801930168

42. Twist C, Eston RG. The effects of exercise-induced muscle damage on maximal intensity intermittent exercise performance. Eur J Appl Physiol. 2005;94:652-658. doi:10.1007/s00421-005-1357-9

43. Byrne C, Eston RG. The effect of exercise-induced muscle damage on isometric and dynamic knee extensor strength and vertical jump performance. J Sports Sci. 2002;20:417-425. doi:10.1080/ 026404102317366672

44. Isner-Horobeti ME, Dufour SP, Vautravers P, Geny B, Coudeyre E, Richard R. Eccentric exercise training: modalities, applications and perspectives. Sports Med. 2013;43(6):483-512. doi:10.1007/s40279013-0052-y

45. Cleak MJ, Eston RG. Muscle soreness, swelling, stiffness and strength loss following intense eccentric exercise. Br J Sports Med. 1992;26:267-272. doi:10.1136/bjsm.26.4.267

46. Oakley AJ, Jennings J, Bishop CJ. Holistic hamstring health: not just the Nordic hamstring exercise. Br J Sports Med. 2018;52(52):816817. doi:10.1136/bjsports-2016-097137

47. Buckthorpe M, Wright S, Bruce-Low S, et al. Recommendations for hamstring injury prevention in elite football: translating research into practice. Br J Sports Med. 2019;53:449-456. doi:10.1136/bjsports2018-099616

\section{Publish your work in this journal}

Open Access Journal of Sports Medicine is an international, peerreviewed, open access journal publishing original research, reports, reviews and commentaries on all areas of sports medicine. The manuscript management system is completely online and includes a very quick and fair peer-review system. Visit http://www.dovepress. com/testimonials.php to read real quotes from published authors. 